\title{
MEASUREMENT of AMMONIA and GLUTAMINE in CELL CULTURE MEDIA by GAS SENSING ELECTRODES
}

\author{
Sadettin S. Ozturk ${ }^{2, *}$, Mark E. Meyerhoff ${ }^{1}$ and Bernhard O. Palsson² \\ Departments of ${ }^{1}$ Chemistry and ${ }^{2}$ Chemical Engineering \\ The University of Michigan, Ann Arbor, MI 48109, USA
}

\section{SUMMARY}

This paper describes the use of a commercially available off-line gas sensing electrode for determination of ammonia and glutamine in cell culture media. The measurement technique was tested in different media preparations with different serum concentrations. The glutamine decomposition was studied as a function of $\mathrm{pH}$ for cell culture medium and the results were compared to those obtained by conventional methods, i.e., HPLC. Finally, glutamine and am. monia metabolism were studied during the cultivation of a hybridoma cell line.

\section{INTRODUCTION}

Glutamine and ammonia are important metabolites in cell culture media used to grow mammalian cells in vitro. It has been shown that giutamine is a major nitrogen and energy source for many mammalian cell lines in culture (Zielke et al., 1984; Miller et al., 1988). The primary waste product of glutamine metabolism is ammonia which is known to inhibit cell growth (Glacken, 1986; Miller et al., 1988). Thus the precise determination of glutamine and ammonia concentrations in cell culture media is important.

Ammonia and glutamine in cell culture media can be determined by a variety of methods. Ammonia can be assayed spectrophotometrically with the enzyme glutamate dehydrogenase (Lund, 1977) or via commercially available ammonia gas sensing electrodes (Miller et al., 1988). Glutamine can be determined enzymatically using combinations of glutaminase/glutamate dehydrogenase or glutaminase/glutamate oxidase. These methods require a second enzymatic reaction and lack selectivity over glutamate (Romette and Cooney, 1987). Presently, HPLC seems to be the most reliable method for glutamine determination. However it is expensive and time consuming.

Glutamine can also be determined directly using the glutaminase enzymatic reaction (Guilbault and Shu, 1971; Arnold and Rechnitz, 1980). In this case, glutamine is converted to glutamate and ammonia. Hence any method for ammonia determination can be used to detect the additional liberated ammonia. Here we utilize a commercially available ammonia electrode for the measurement of both ammonia and glutamine. This paper outlines the procedure and its application to cell culture media.

\section{MATERIALS AND METHODS}

Determination of ammonia and glutamine. Cell culture media Iscove's Modified Eagle's Medium (IMDM, Gibco Laboratories, Grand Island, NY, USA), RPMI-1640 (Sigma Chemical Company, St. Louis, MO, USA) and OPTI-MEM (Gibco) were obtained from respective commercial sources. The media was prepared according to the instructions provided by the 
manufacturer. The culture $\mathrm{pH}$ was adjusted using sodium bicarbonate (Sigma). For different glutamine concentrations, phosphate buffer saline (PBS) was used to dilute the original media preparation. Ammonia standards were prepared using ammonium chloride (Sigma).

A commercial ammonia gas sensing electrode was used for all measurements (Orion, Boston, MA, USA). For ammonia determinations, $100 \mu$ of the sample was diluted with 500 $\mu \mathrm{l}$ of $\mathrm{pH}$ adjusting buffer solution (Orion) and the potentiometric response of the electrode was recorded on a pH meter (Beckman) using the $\mathrm{mV}$ scale. A typical response time was about $1 \mathrm{~min}$. An ammonia calibration curve was established by serially diluting ammonium chloride standards. This curve was used to convert the $\mathrm{mV}$ values to ammonia concentrations.

For glutamine determinations, first the initial ammonia in each sample was measured using the above procedure. Glutamine was then measured by the same electrode after enzymatic reaction with glutaminase (Sigma). The enzyme was kept as a $25 \mathrm{Units} / \mathrm{ml}$ stock solution in $0.005 \mathrm{M}$ acetate buffer, $\mathrm{pH} 6$. For the analysis, the stock solution of enzyme was diluted to $5 \mathrm{Units} / \mathrm{ml}$. A mixture of acetate buffer $(40 \mu l, 0.1 \mathrm{M}, \mathrm{pH} 4.9)$, sample $(50 \mu l)$ and the glutaminase $(10 \mu l)$ was incubated at $37^{\circ} \mathrm{C}$ for $15 \mathrm{~min}$. After this period, $500 \mu \mathrm{l}$ of the pH adjusting buffer solution was added to the mixture and the final ammonium concentration was measured with the electrode. Since the ammonia in the samples had been determined before the glutaminase reaction, the additional ammonia generated can be directly related to the concentration of glutamine present.

Glutamine decomposition. The decomposition rate of glutamine was studied in IMDM (Gibco). Using sodium bicarbonate (Sigma) and fetal bovine serum (FBS, Gibco) a series of IMDM with different pHs and serum concentrations was prepared. No antibiotics were added. The solutions were transferred into $50 \mathrm{ml}$ sterile T-flasks $(10 \mathrm{ml}$ working volume) and were placed in an incubator at $37^{\circ} \mathrm{C}$ and $5 \% \mathrm{CO}_{2}$. Samples $(0.5 \mathrm{ml})$ were taken periodically and frozen at $-20^{\circ} \mathrm{C}$. At the end of the experiment, the samples were thawed and analyzed for ammonia and glutamine using the procedures outlined above.

For the determination of glutamine by HPLC, the OPA (ortho-phthaldialdehyde) pre-column derivitization method was employed (Hill et al. 1979). The mobile phase was a mixture of solvent $\mathrm{A}(90 \% 0.1 \mathrm{M}$ sodium acetate $\mathrm{pH} 7.2 / 9.5 \%$ methanol/ $0.5 \% \mathrm{THF})$ and solvent $\mathrm{B}(100 \%$ methanoi). The samples were diluted by 20 fold in solvent $A$ and $100 \mu l$ of this mixture was reacted with $200 \mu \mathrm{l}$ OPA for $2 \mathrm{~min}$. A $25 \mu \mathrm{l}$ fraction of the derivatized sample was injected onto a Microsorb C18 column (Rainin Instrument Co., Inc., Emeryville, CA, USA). The HPLC system used to separate glutamine from the other amino acids was a Rabbit-HP equipped with fluorescence detector (Rainin).

Glutamine and ammonia metabolism of hybridoma cells. The murine hybridoma used was 167.4G5.3, kindly provided by Dr. J. Latham Claflin from the University of Michigan (Department of Microbiology and Immunology). The antibody produced by this cell line is a T15 idiotype family of $I g G_{1}$ directed against phosphorylcholine (Briles et al., 1984). A 1.5 It Celligen bioreactor (New Brunswick) with $\mathrm{pH}$ and dissolved oxygen control was used for the study of cellular metabolism and the rate of monoclonal antibody production. The medium was Iscove's Modified Dulbecco's Medium containing $10 \%$ fetal bovine serum (Gibco) and $1 \%$ antibiotic/antimycotic solution; 10,000 U penicillin, $10 \mathrm{mg}$ streptomycin, and $25 \mu \mathrm{g}$ amphotericin B per $\mathrm{ml}$ (Sigma).

The cells were propagated in $75 \mathrm{~cm}^{2}$ T-flasks by serially passing them every day. These exponentially growing cells were centrifuged at $1000 \mathrm{rpm}$ for $10 \mathrm{~min}$ and washed with fresh medium. They were then inoculated into the reactor at an initial concentration of $4 \cdot 10^{4} \mathrm{cells} / \mathrm{ml}$. The temperature of the reactor was kept at $37^{\circ} \mathrm{C}$, with the $\mathrm{pH}$ and dissolved oxygen tension of the medium kept at 7.2 and $20 \%$ air saturation respectively. The agitation rate was at 80 $\mathrm{rpm}$. Samples were taken twice daily in $2 \mathrm{ml}$ volumes. Cells in suspension were counted in a 


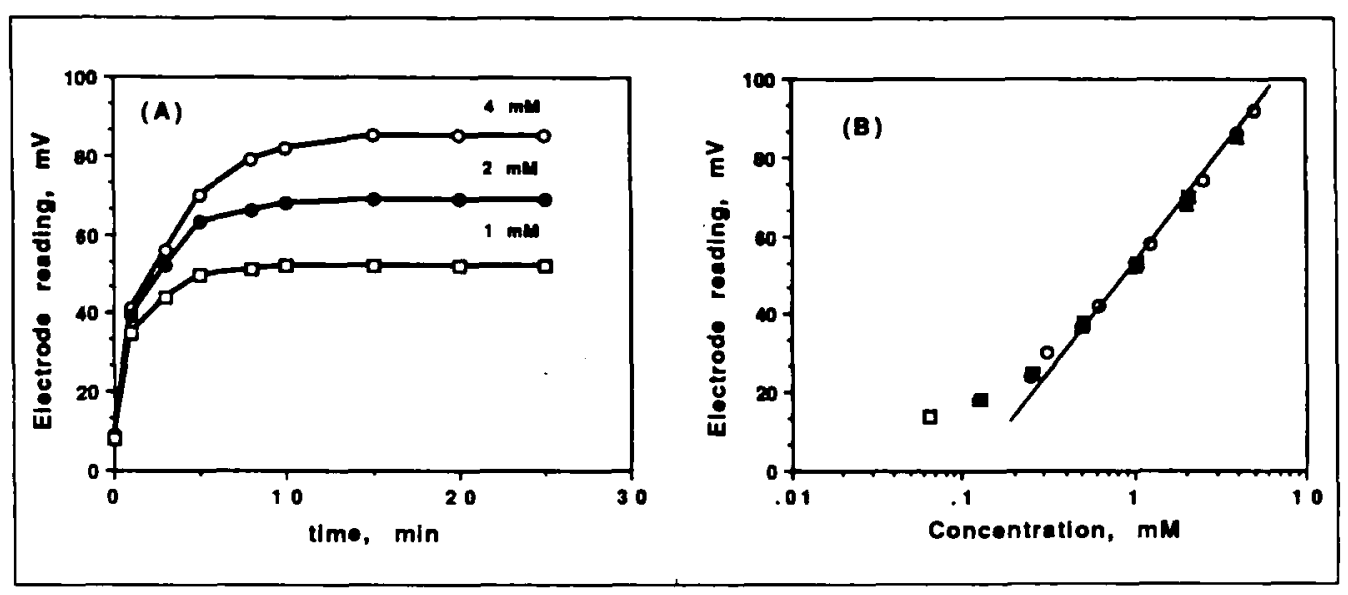

Figure 1: (A) Dynamics of glutamine determination in Iscove's modified Dubelco's Medium (IMDM), (B) Calibration curve for ammonia (open circle) and for different cell culture media formulations, i.e., IMDM (uriangle), RPMI-1640 (square), OPTI-MEM (closed circle). The electrode readings are in negative potential values in $\mathrm{mVs}$.

hemacytometer. Cell viability was determined by the trypan blue exclusion method. After the cell counts, the samples were centrifuged at $1000 \mathrm{rpm}$ for $10 \mathrm{~min}$. The supernatant were kept frozen at $-20^{\circ} \mathrm{C}$ for later analysis of the metabolite and antibody concentrations.

Glucose and lactate concentrations in the cell culture media were measured using a Model 2000 Glucose/L-Lactate analyzer (Yellow Springs Instruments, Yellow Springs, OH, USA). Antibody $I g G_{1}$ was quantitated using an enzyme linked immunosorbent assay (ELISA). Ammonia and glutamine were determined as outlined above.

\section{RESULTS AND DISCUSSION}

Typical kinetics of the enzymatic glutamine determination is shown in Fig. 1A. The samples were buffered at $\mathrm{pH} 4.9$ and the enzyme was added as described in Materials and Methods section. The incubation time with the enzyme was varied for each concentration of glutamine. As shown in the figure, steady potential readings were established after 10-15 min of incubation and these equilibrium $\mathrm{mV}$ readings were concentration dependent. The concentrations given in the figure are the values for the glutamine levels in the original standards and they do not include the dilutions with buffer, enzyme and the $\mathrm{pH}$ stabilizing agent. A typical calibration curve is presented in Fig. 1B. Again here the concentrations in the original samples were used on the ordinate. The data for other media was also included in this calibration curve. Also included in Fig. $1 \mathrm{~B}$ is the calibration curve for ammonia. It is clear that the type of media is not important for the glutamine determination; indeed the calibration curve for ammonia can be used to infer the glutamine concentrations. The logarithmic response is clear above a concentration of 0.2 $\mathrm{mM}$ below which the method loses sensitivity. 


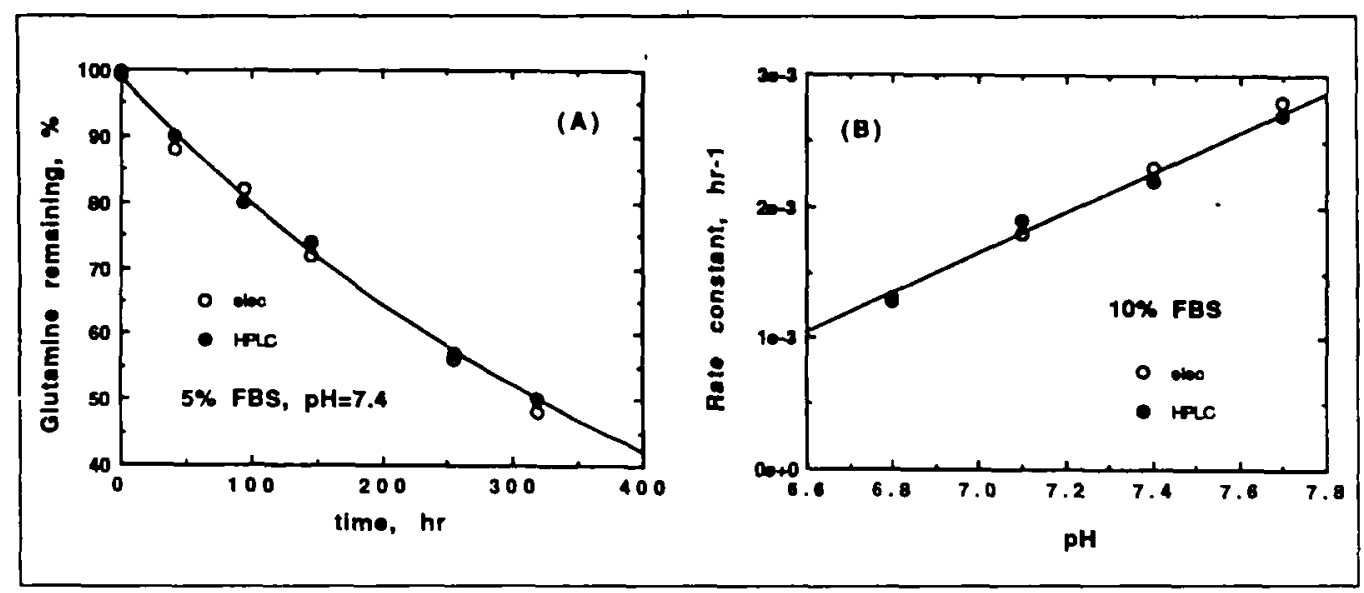

Figure 2: Decomposition of glutamine at different $\mathrm{pH}$ values for IMDM. (A) Glutamine concentration profiles for IMDM with 5\% FBS, $\mathrm{pH}=7.4$, and (B) rate constants for different $\mathrm{pH}$ values in IMDM with 10\% FBS. Comparison of electrode method (open circles) and HPLC (closed circle).

The glutamine decomposition rate is shown in Fig. 2 for two different serum concentrations and different $\mathrm{pH}$ values. In Fig. 2A the glutamine profile is presented for IMDM containing 5\% FBS at pH 7.4. The data from the electrode method was in good agreement with values determined by the HPLC method. The data may be used to evaluate the first order decomposition constant for glutamine:

$$
-\frac{[G l n]}{d t}=k[G l n]
$$

where $[G l n]$ is glutamine concentration, $t$ is time and $k$ is the first order rate constant. The data was fitted with such a model and the value of $k$ was extracted. The solid line in Fig. $2 \mathrm{~B}$ presents the model fit to the data with a $k$ value of $0.0023 h^{-1}$. Similar data was obtained for $10 \%$ serum which is presented in Fig. $2 \mathrm{~B}$ as a function of $\mathrm{pH}$. The values of rate constant obtained from electrode and HPLC methods were also comparable. The values were correlated by a regression coefficient more than $96 \%$ (data not shown). The half life of glutamine was found to be between 7-10 days. There is no data for decomposition rate of glutamine in IMDM, however the values of rate constant determined here are comparable with the data of Lin and Agrawal (1988) for glutamine in DMEM $\left(0.001<k<0.004 \mathrm{hr}^{-1}\right)$ and the data of Miller et al., (1988) for glutamine in DMEM with $10 \%$ serum $\left(k=0.002 \mathrm{hr}^{-1}\right.$ at $\left.\mathrm{pH}=7.2\right)$.

The growth and metabolism of hybridoma cell line $167.4 \mathrm{G} 5.3$ is shown in Fig. 3. The viable cell counts increased in a logarithmic fashion at first reaching a plateau which was followed later by a decline phase (Fig. 3A). As shown in Fig. 3A, the antibody $I g G_{1}$ concentration increased gradually. This $I g G_{1}$ production continued in the decline phase. Glucose and lactate concentrations during this cultivation period are presented in Fig. 3B. Note that only half of the glucose was utilized.

Figures $3 \mathrm{C}$ and $3 \mathrm{D}$ show data for glutamine and ammonia over the same cultivation period 


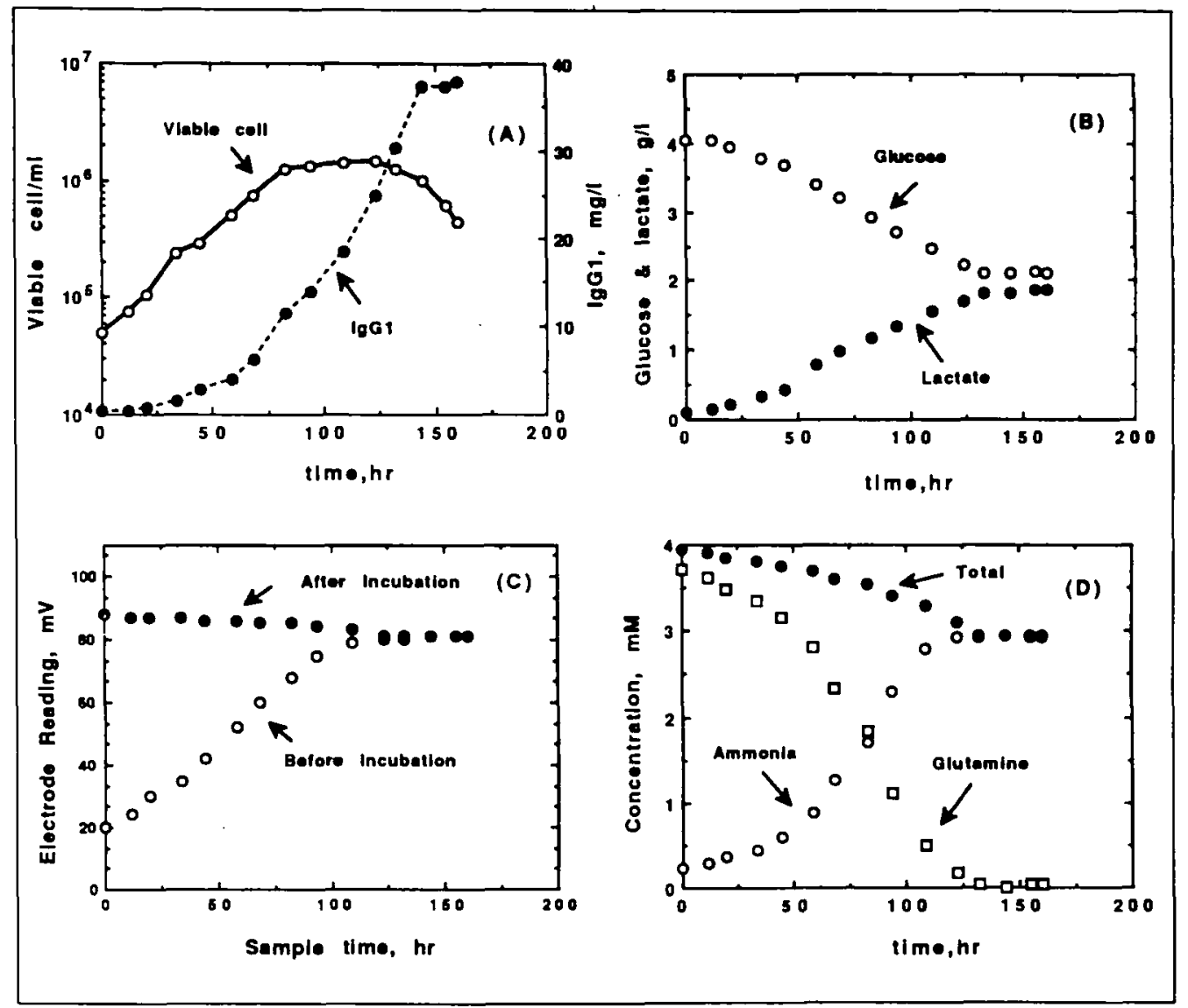

Figure 3: Growth and cell metabolism of hybridoma cell line 167.4G5.3. (A) Cell growth (open circle) and MAb production (closed circle), (B) Glucose (open circle) and lactate (closed circle) metabolism, (C) Electrode readings before enzymatic incubation (background ammonia, open circle) and after enzymatic incubation (ammonia generated from glutamine plus initial ammonia, closed circle), (D) the resulting ammonia (open circles) and glutamine (squares) concentrations obtained. The closed circles indicate the total ammonia concentration (initial ammonia plus ammonia from glutamine) 
as measured with the present gas sensing electrode method. The samples were incubated with the enzyme for $15 \mathrm{~min}$ and the corresponding readings were obtained for the initial ammonia plus the ammonia generated from glutamine. Since the response of electrode is logarithmic, the responses in $\mathrm{mV}$ cannot be substracted to get a $\mathrm{mV}$ response for glutamine. Instead, each electrode reading was converted to concentrations (Fig. 3D) using the standard curve prepared from ammonia calibration. Thus, initial ammonia (from the initial readings) and the total ammonia concentrations were obtained. From the reaction stoichiometry, one mole of ammonia is generated for one mole of glutamine. Therefore, the difference in total and initial ammonia levels is directly related to glutamine concentration. These values are presented in Fig. 3D. As shown in this figure glutamine is depleted after $120 \mathrm{hr}$ of operation which coincides with the start of the death or decline phase of the growth (Fig. 3A). These results once again indicate that glutamine is a very important nutrient for hybridoma cell growth and, in fact, is the limiting nutrient under the cell culture conditions used here. The glutamine concentrations measured by the electrode method were again compared with those from HPLC method and it was found that they correlated each other with a regression coefficient of $96.5 \%$ (data not shown).

\section{CONCLUSIONS}

We have demonstrated the use of a simple gas sensing electrode based method for determination of ammonia and glutamine in cell culture media. The glutamine decomposition and glutamine metabolism rates in media were studied using this technique. The electrode method provides very fast results and the values compare favorably with the more laborious conventional HPLC method. We have not seen any complications with serum, with $\mathrm{pH}$, and with media composition. Although the electrode method is less sensitive at very low concentrations, the concentration ranges for ammonia and glutamine in cell culture media are sufficiently high so that accurate results can be obtained.

Acknowledgement This work was supported by National Science Foundation Grant No. EET8712756. The authors thank Dr. J. Latham Claflin for providing the hybridoma cell line used in this study.

\section{REFERENCES}

Arnold, M., and Rechnitz, G. A., Anal. Chem., 52, 1170-1174 (1980).

Briles, D. E., Forman, C., Hudak, S., and Claflin J. L., Eur. J. Immunol., 14, 1027-1030 (1984)

Fraticelli, Y. M. and Meyerhoff, M. E., Anal. Chem. 53, 992 (1981)

Glacken, M. W., Fleischaker, R. J., and Sinskey, A. J., Biotechol. Bioeng, 28, 1676-1389 (1986)

Guilbault, G. G. and Shu, F. R., Anal. Chim. Acta., 56, 333 (1971)

Hill, D. W., Walters, F. H., Wilson, T. D., and Stuart, J. D., Anal. Chem., 51, 1338 (1979).

Lin, A., and Agrawal, P., Biolech. Lellers, 10, 695-698 (1988)

Lund, P., in Methods of Enzymatic Analysis, H. V. Bergmeyer, Ed. (Verlag Chemie International, Deerfield Beach. FL. 1977) p. 1719

Miller, W. M., Blanch, H. W., and Wilke, C. R., Biolechnol. Bioeng., in print (1988)

Romette, J. L., and Cooney, C. L., Anal. Lett., 20, 1069, (1987)

Zielke, H. R., Zielke, C. L., and Ozand, P. T., Federation Proc., 43, 121-125 (1984). 